\title{
Evolutionary divergence of the oncogenes GLI, HST and INT2
}

\author{
ROBERT A. CONTE, RHEA V. SAMONTE† \& RAM S. VERMA* \\ Division of Genetics, The Long Island College Hospital - SUNY Health Science Center at Brooklyn, 339 Hicks Street, \\ NY 11201-5514, U.S.A.
}

\begin{abstract}
Almost a quarter of a century ago, the banding patterns of human and other higher primate chromosomes were compared, creating a barrage of speculation. Consequently, a number of approaches have been used to understand human descent. Chromosome modifications are believed to be important in the origin of species, and pericentric inversions account for the majority of evolutionary chromosomal alterations seen in Hominoidea. A comparative mapping fluorescence in situ hybridization technique, using locus-specific DNA probes as phylogenetic markers, was used to decipher the pericentric inversions of human chromosomes 11 and 12. Human-derived (Homo sapiens, HSA) DNA probes for GLI, HST and INT2 protooncogenes were used to identify their homologous locations in the chromosomes of chimpanzee (Pan troglodytes, PTR), gorilla (Gorilla gorilla, GGO) and orangutan (Pongo pygmaeus, PPY). The INT2 and HST loci mapping results confirm the earlier putative claim that a pericentric inversion took place in HSA chromosome 11 and its equivalent PTR and GGO chromosomes. In addition, these data provide additional information regarding the orangutan's position on the evolutionary tree of Pongidae and Hominidae. GLI mapping reveals that a pericentric inversion occurred in the HSA chromosome 12 equivalent in PTR and GGO, but was not seen in HSA or PPY. These pericentric inversions in PTR and GGO may have occurred at a period when both PTR and GGO had branched off from the Hominoidae trunk. The use of loci-specific probes to decipher pericentric inversions has proved to be a formidable approach in characterizing chromosome rearrangements and providing further evidence on human descent.
\end{abstract}

Keywords: chimpanzee, gorilla, human chromosomes 11 and 12, oncogenes, orangutan, primate evolution.

\section{Introduction}

Most DNA sequence studies on the higher primates place chimpanzee closest to human on the phylogenetic tree, followed by gorilla and then orangutan (Bailey et al., 1992; Horai et al., 1992; Marks, 1992; Ruvolo, 1994). A comparison of karyotypic data from various primates supports this general claim, which is still being debated (Dutrillaux \& Rumpler, 1988). Phylogenetic analysis by means of chromosome banding patterns in human (Homo sapiens, HSA), chimpanzee (Pan troglodytes, PTR), gorilla (Gorilla gorilla, GGO) and orangutan (Pongo pygmaeus, PPY) reveals that pericentric inversions may be a significant evolutionary mechanistic factor (Dutrillaux et al., 1986; Miro et al., 1992). Approximately 20 pericentric inversions have apparently occurred during the period of hominoid chromosome evolution (Yunis \& Prakash, 1982). These alterations, which have been determined by routine banding techniques, warrant a fine characterization, which is best served by the availability of a large body of comparative mapping data. The use of the fluorescence in situ hybridization (FISH) technique using chromosome- and loci-specific DNA probes provides a useful tool for determining chromosomal evolutionary convergence/divergence (Jauch et al., 1993; O'Brien, 1993; Luke \& Verma, 1995). The present study maps the homologous locations of the human GLI, HST and INT2 proto-oncogenes comparatively in order to investigate higher primate chromosome evolution in the human-equivalent chromosomes 11 and 12. The established idiogram based on G-banding of great ape chromosomes reveals changes in chromosome pattern and centromere position for chromosomes HSA 11, PTR 9, GGO 9, PTR 10 and GGO 10 (Figs 1 and 2). 


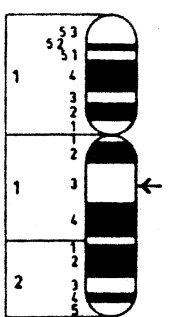

HSA 11

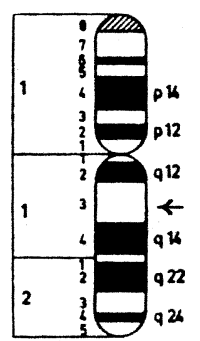

PTR 9

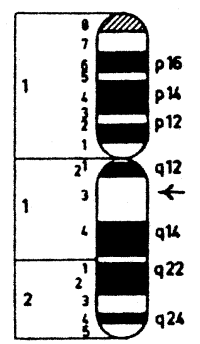

GGO 9

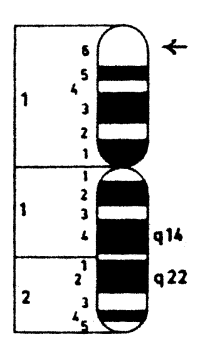

PPY 8
Fig. 1 Representation of chromosome bands for human (HSA 11), chimpanzee (PTR 9), gorilla (GGO 9) and orangutan (PPY 8). Arrows indicate the human-equivalent banding designation determined by comparative mapping of the INT2 and HST oncogene homologous sequences (see ISCN, 1985).

Apparently, cytogenetic data for chromosome 11 agree with the previous molecular phylogeny, whereas data for chromosome 12 do not. FISH using these oncogene loci DNA probes may shed light on the rearrangements suggested by G-banding.

\section{Materials and methods}

Great ape chromosomes (Pan troglodytes, GMO 3450 and AGO 6939A; Gorilla gorilla, AGO 5251A and ATCC CRL 1854; and Pongo pygmaeus, GMO 4272 and AGO 5252) were prepared from fibroblast cell lines provided by NIGMS Human Genetic Mutant Cell Repository at the Coriell Institute for Medical Research (Camden, NJ, U.S.A.) and the American Type Culture Collection (Rockville, MD, U.S.A.).

Metaphase chromosomes were obtained using the standard fibroblast harvesting procedure (Verma \& Babu, 1995). Human chromosomes were prepared

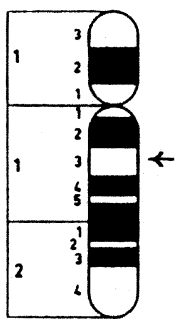

HSA 12

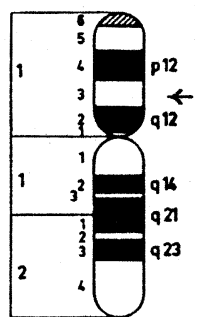

PTR 10

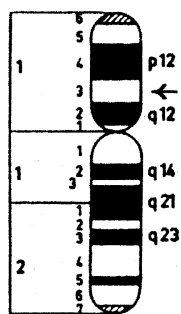

GGO 10

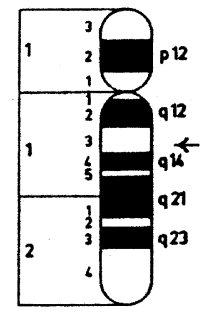

PPY 9
Fig. 2 Representation of chromosome bands for human (HSA12), chimpanzee (PTR 10), gorilla (GGO 10) and orangutan (PPY 9). Arrows indicate the human-equivalent banding designation determined by comparative mapping of the GLI oncogene homologous sequences (see ISCN, 1985). from phytohaemagglutinin (PHA)-stimulated blood lymphocytes from a cytogenetically normal individual. The FISH technique according to Pinkel et al. (1986) was used with minor modifications as suggested by the manufacturer (Oncor, Gaithersburg, MD, U.S.A.). The following unique sequence probes were used: HST and INT2, which detect a locus in the human chromosome band 11q13.3, and GLI, which detects a locus in the human chromosome band 12q13. All three probes were digoxigenin labelled. Briefly, target chromosome DNA was heat denatured in $70 \%$ formamide $/ 2 \times \mathrm{SSC}(\mathrm{pH} 7.0)$ at $72^{\circ} \mathrm{C}$. Overnight hybridization was performed at $37^{\circ} \mathrm{C}$ in a humid chamber. Posthybridization washes were in $2 \times \operatorname{SSPE}\left(\mathrm{pH} \mathrm{7.4)}\right.$ ) at $72^{\circ} \mathrm{C}$ for $5 \mathrm{~min}$. Detection was performed using fluorescein isothiocyanate (FITC)-conjugated antidigoxigenin. Chromosomes were counterstained with propidium iodide/antifade. Photomicrographs were taken using a FITC filter under fluorescent conditions. Chromosomes were preidentified by the QFQ-banding technique.

\section{Results and discussion}

GLI, HST and INT2 unique sequence human oncogene DNA probes were hybridized to metaphase chromosomes of HSA, PTR, GGO and PPY using the FISH technique to determine phylogenetic position concordance or discordance. The homologous sequences of these proto-oncogenes revealed in the great ape chromosomes were indicated by positive hybridization signals. HST and INT2 are both members of the fibroblast growth factor (FGF)-related gene family and have been localized to human chromosome band 11q13.3 (Dickson \& Peters, 1987; Marics et al., 1989). The GLI oncogene is a zinc finger transcription factor and has been localized to human chromosome band 12q13 (Dal Cin et al., 1989; Kinzler \& Vogelstein, 1990). FISH data using Hominoidea metaphase chromosomes demonstrate that the HST and INT2 sequences map to a HSA 11 concordant region in PTR and GGO chromosome 9, corresponding band q13, but map to a discordant location in PPY 8 at band p16 (Fig. 3). These data suggest that these divergent oncogene positions are apparently caused by pericentric inversions, which may have occurred in the human chromosome 11 equivalent of a common ancestor for HSA, PTR and GGO. This supports the cladogram from Dutrillaux \& Rumpler (1988), which states that PPY separated first from the common trunk of the evolutionary tree for Pongidae and Hominidae. These pericentric inversions may have occurred at a period between the beginning of a 
common trunk for HSA, PTR and GGO and after the separation of PPY from the Pongidae lineage.

The FISH data from the GLI probe reveal that it maps to a concordant position in PPY 9 at band q13 to discordant locations in PTR 10 and GGO 10 at corresponding band p13 (Fig. 3). Routine staining has shown that PTR 10 has been modified by a pericentric inversion (Dutrillaux \& Rumpler, 1988). An idiogram based on G-banding suggests that this pericentric inversion also occurred in GGO 10 (ISCN, 1985). The GLI FISH data of this study support this concept. These chromosomal modifications in PTR 10 and GGO 10 may have occurred at a common trunk for PTR and GGO, after the event when populational evolution occurred, at the end of a common trunk for HSA, PTR and GGO (Dutrillaux \& Rumpler, 1988). Ribosomal DNA studies may also provide evidence that PTR and GGO shared an exclusive common trunk (Marks, 1983). However, if this is not the case, then explanations

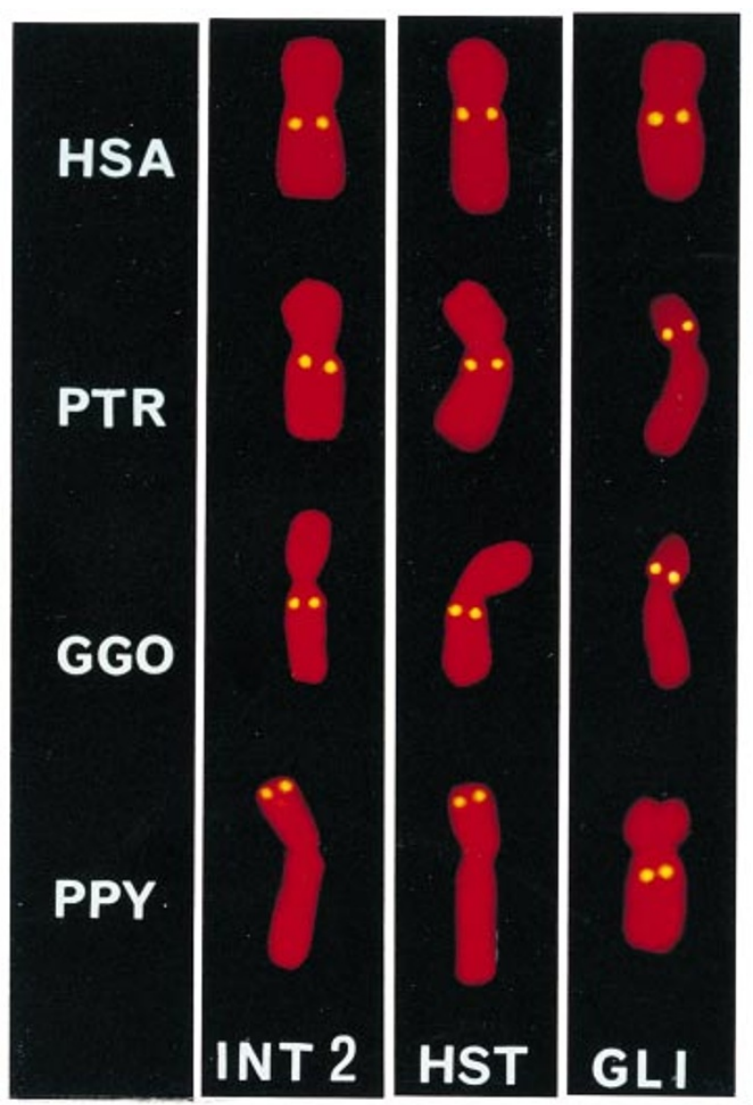

Fig. 3 INT2 and HST loci in human (HSA 11), chimpanzee (PTR 9), gorilla (GGO 9) and orangutan (PPY 8) chromosomes. GLI locus in human (HSA 12), chimpanzee (PTR 10), gorilla (GGO 10) and orangutan (PPY 9). Diagrammatic representations of chromosome bands are shown in Figs 1 and 2. may include a potential back-mutation in HSA 12 or a possible polymorphism for the two states of chromosome 12 in the GGO/PTR/HSA ancestor continuing to the PTR/HSA ancestor, with subsequent fixation of alternate states in GGO and PTR (in one respect) and humans (in the other). A comparative mapping database can be established using other unique sequence probes to determine evolutionary relationships among the primates and, ultimately, to advance elucidation of the phylogenetic pathway of human descent.

\section{Acknow ledgements}

We are indebted to Robert Robinson for superb photography and Mark A. R. Sealy for typing.

\section{References}

BAIley, W. J., HAYASAKA, K., SKINNER, C. G., KeHOE, S., SiEU, L. C., SLightom, J. L. AND Goodman, M. 1992. Reexamination of the African Hominoid trichotomy with additional sequences from the primate beta-globin gene cluster. Mol. Phylogenet. Evol., 1, 97-135.

DAL CIN, P., TURC-CAREL, C., SANBERG, A. A. AND VAN DEN BERGHE, H. 1989. More precise localization of GLI gene by in-situ hybridization (abstract). Cytogenet. Cell Genet., 51, 982-983.

DiCKSON, C. AND PETERS, G. 1987. Potential oncogene product related to growth factors. Nature, 326, 833 .

DUTRIllauX, B. AND RUMPleR, Y. 1988. Chromosome evolution in primates. Folia Primatol., 50, 134-135.

DUtrillauX, B., COUTURIER, J., SABATIER, L., MUleris, M. AND PRIEUR, M. 1986. Inversions in evolution of man and closely related species. Ann. Genet., 29, 195-202.

HORAI, S., SATTA, Y., HAYASAKA, K., KONDO, R., INOUE, T., ISHIDA, T. ETAL. 1992. Man's place in Hominoidea revealed by mitochondrial DNA geneology. J. Mol. Evol., 35, 32-43.

ISCN 1985. An International System for Human Cytogenetic Nomenclature, Harnden, D. G. \& Klinger, H. P. (eds), pp. 100-109. Karger, Basel.

JAUCH, A., WIENBERG, J., STANYON, R., ARNOLD, N., TOFANELLI, S., ISHIDA, T. AND CREMER, T. 1993. Reconstruction of genomic rearrangements in great apes and gibbons by chromosome painting. Proc. Natl. Acad. Sci. U.S.A., 89, 8611-8615.

KINZLER, K. W. AND VOGELSTEIN, N. 1990. The GLI gene encodes a nuclear protein which binds specific sequences in the human genome. Mol. Cell Biol., 10, 634-642.

LUKE, S. AND VERMA, R. S. 1995. The genomic sequence for Prader-Willi/Angelman syndromes' loci of human is apparently conserved in the great apes. J. Mol. Evol., 41, 250-252.

MARICS, I., ADELAIDE, J., RAYBAUD, F., MATTEI, M.-G., COULIER, F., PLANCHE, J. ET AL. 1989. Characterization of 
the HST-related FGF6 gene, a new member of the fibroblast growth factor gene family. Oncogene, 4, $335-340$.

MARKs, J. 1983. Hominoid cytogenetics and evolution. Yearbk. Phys. Anthropol., 26, 131-159.

MARKS, J. 1992. Genetic relationships among the apes and humans. Curr. Opin. Genet. Dev., 2, 883-889.

MIRo, R., FUSTER, C., ClEMENETE, K., CABALlin, M. R. AND EgOzCue, J. 1992. Chromosome inversions involved in the chromosome evolution of the Hominidae and in human constitutional chromosome abnormalities. $J$. Hum. Evol., 22, 19-22.

o'Brien, s. J. 1993. The genomics generation. Curr. Biol.,
3, 395-397.

PINKEl, D., STRAume, T. AND GRAY, J. w. 1986. Cytogenetic analysis using quantitative high sensitivity fluorescence hybridization. Proc. Natl. Acad. Sci. U.S.A., 83, 2934-2938.

RUVUlO, M. 1994. Molecular evolutionary processes and conflicting gene trees: the hominoid case. Am. J. Phys. Anthropol., 94, 89-113.

VERMA, R. S. AND BABU, A. 1995. Human Chromosomes: Principles and Techniques. McGraw-Hill, New York.

YUNIS, J. J. AND PRAKASH, O. 1982. The origin of man: a chromosome pictorial legacy. Science, 215, 1525-1530. 